\title{
A New Comprehensive Classification System for both Lower and Upper Urinary Tract Dysfunction in Patients with Neurogenic Bladder
}

\author{
Limin Liao \\ Department of Urology, China Rehabilitation Research Center, and Department of Urology, Capital Medical \\ University, Beijing, China
}

Urinary incontinence, hydronephrosis $(\mathrm{HN})$, and vesicoureteral reflux (VUR) are devastating problems for patients with neurogenic bladder (NB) because such complications often indicate the presence of increased bladder pressure. Elevated intravesical pressure can be transmitted to the upper urinary tract (UUT), causing HN and ureteral dilation (UD), which are referred to as UUT dilation (UUTD) $[1,2]$. Ureteral obstruction at the bladder wall is also a cause of UUTD. Therefore, the evaluation and protection of UUT function is extremely important in the treatment of NB dysfunction. The International Reflux Study Group (IRSG) classification is widely used for grading VUR [3]; however, there is little agreement on the degree of UUTD that signifies HN. The Society for Fetal Urology (SFU) grading system for $\mathrm{HN}$ is a subjective system [4]; however, the classification of UUTD, including HN and UD for patients with NB, is still a matter of debate. The existing classification schemes for lower urinary tract dysfunction (LUTD) have only focused on the bladder and urethra and do not relate to UUTD, including HN, VUR and UD $[1,2,5]$. In a previous study,
I described a new UUTD grading system, including $\mathrm{HN}$ and $\mathrm{UD}$, based on magnetic resonance urography (MRU) [6]. Herein I describe a new comprehensive classification system for lower and upper urinary tract dysfunction in patients with NB (table 1).

In table 1, LUTD is described according to the Guidelines of the European Association of Urology (EAU) [2] and the terminology of the International Continence Society (ICS) [5]. VUR was graded according to the IRSG, and kidney function was determined by the glomerular filtration rate from isotope renography and the serum level of creatinine. UUTD was graded as follows: grade 0 , the central renal complex is closely apposed without UD (fig. 1a); grade 1 , slight separation of the central renal complex exists, and the ureter is $<7 \mathrm{~mm}$ in diameter (fig. 1b); grade 2, the renal pelvis is further dilated, a single or a few calices may be visualized and the ureter is $<10 \mathrm{~mm}$ in diameter (fig. 1c); grade 3 , the renal pelvis is dilated, there are fluid-filled calices throughout the kidney, the renal parenchyma overlying the calices has thinned (renal parenchyma loss $<50 \%$ ), and the ureter is tortuous and $<15 \mathrm{~mm}$ in diameter (fig. 2a), and grade 4 , similar to grade 3 , but the renal parenchyma over the calices is thinned (renal parenchyma loss $>50 \%$ ), the ureter is severely tortuous and the ureter is $>15 \mathrm{~mm}$ in diameter (fig. 2b). For NB patients, detrusor fibrosis and thickening secondary to progressive destruction of the bladder wall often result in ureteral strictures within the bladder wall and distal ureteral obstruction (fig. 2c), which is an important factor in the etiology of UUTD, including HN and UD, and often results in chronic renal failure. Therefore, this new system better discriminates among grade changes in UUT function, can provide objective indicators for UUT function and is an important component of long-term follow-up of conservative and surgical treatment (fig. 3).

\section{Acknowledgment}

This study was supported by the China National Key Technology R\&D Program (No. 2012BAI34B02).

\section{KARGER 125}

C 2014 S. Karger AG, Base

0042-1138/14/0942-0244\$39.50/0
Limin Liao, MD, $\mathrm{PhD}$

Department of Urology, China Rehabilitation Research Center 10 Jiaomen Beilu, Fentai District Beijing 100068 (China)

E-Maillmliao@263.net 
Table 1. A new comprehensive classification system for lower and upper urinary tract dysfunction in patients with NB

\begin{tabular}{|c|c|}
\hline \multicolumn{2}{|l|}{ LUT } \\
\hline storage & voiding \\
\hline Bladder function & Bladder function \\
\hline Detrusor activity & Detrusor contractility \\
\hline Normal & Normal \\
\hline Overactive & Underactive \\
\hline Bladder sensation & Acontractile \\
\hline Normal & Urethral function \\
\hline Increased or hypersensitive & Normal \\
\hline Reduced or hyposensitive & Obstruction \\
\hline Absent & Urethral overactivity \\
\hline $\begin{array}{l}\text { Bladder capacity } \\
\text { Normal }^{1}(300-500 \mathrm{ml}) \\
\text { High }(>500 \mathrm{ml}) \\
\text { Low }(<300 \mathrm{ml})\end{array}$ & $\begin{array}{l}\text { Detrusor external sphincter dyssynergia } \\
\text { Detrusor bladder neck dyssynergia } \\
\text { Sphincter overactivity (nonrelaxing } \\
\text { sphincter, nonrelaxing bladder neck) }\end{array}$ \\
\hline \multicolumn{2}{|l|}{$\begin{array}{l}\text { Bladder compliance } \\
\text { Normal }\left(20-40 \mathrm{ml} / \mathrm{cm} \mathrm{H}_{2} \mathrm{O}\right) \\
\text { High }\left(>40 \mathrm{ml} / \mathrm{cm} \mathrm{H}_{2} \mathrm{O}\right) \\
\text { Low }\left(<20 \mathrm{ml} / \mathrm{cm} \mathrm{H}_{2} \mathrm{O}\right)\end{array}$} \\
\hline \multicolumn{2}{|l|}{$\begin{array}{l}\text { Urethral function } \\
\text { Normal } \\
\text { Sphincter acontractility } \\
\text { Incompetent } \\
\quad \text { Bladder neck } \\
\quad \text { External sphincter }\end{array}$} \\
\hline \multicolumn{2}{|l|}{ UUT } \\
\hline \\
\hline & \\
\hline \multicolumn{2}{|l|}{$\begin{array}{l}\text { Yes: unilateral, bilateral } \\
\text { Degrees (left, right) I-V }\end{array}$} \\
\hline \multicolumn{2}{|l|}{ UUTD (HN and UD) } \\
\hline \multicolumn{2}{|l|}{ No } \\
\hline \multicolumn{2}{|l|}{$\begin{array}{l}\text { Yes: unilateral, bilateral } \\
\text { Grades (left, right) } 1-4\end{array}$} \\
\hline \multicolumn{2}{|c|}{$\begin{array}{l}\text { Ureteral obstruction in bladder wall } \\
\text { No } \\
\text { Yes (left, right) }\end{array}$} \\
\hline $\begin{array}{l}\text { Renal function } \\
\text { Normal (GFR }>50 \mathrm{ml} / \mathrm{min} \text {, le } \\
\text { Renal insufficiency (GFR }<50 \\
\text { Compensatory (GFR, left, rig } \\
\text { Decompensation (GFR, left, }\end{array}$ & $\begin{array}{l}\text { right) } \\
<1.5 \mathrm{mg} / \mathrm{dl}) \\
\text { e }>1.5 \mathrm{mg} / \mathrm{dl})\end{array}$ \\
\hline
\end{tabular}

${ }^{1}$ For adults. LUT = Lower urinary tract; UUT = upper urinary tract; GFR = glomerular filtration rate.
Classification System for Urinary Tract Dysfunction in Neurogenic Bladder 

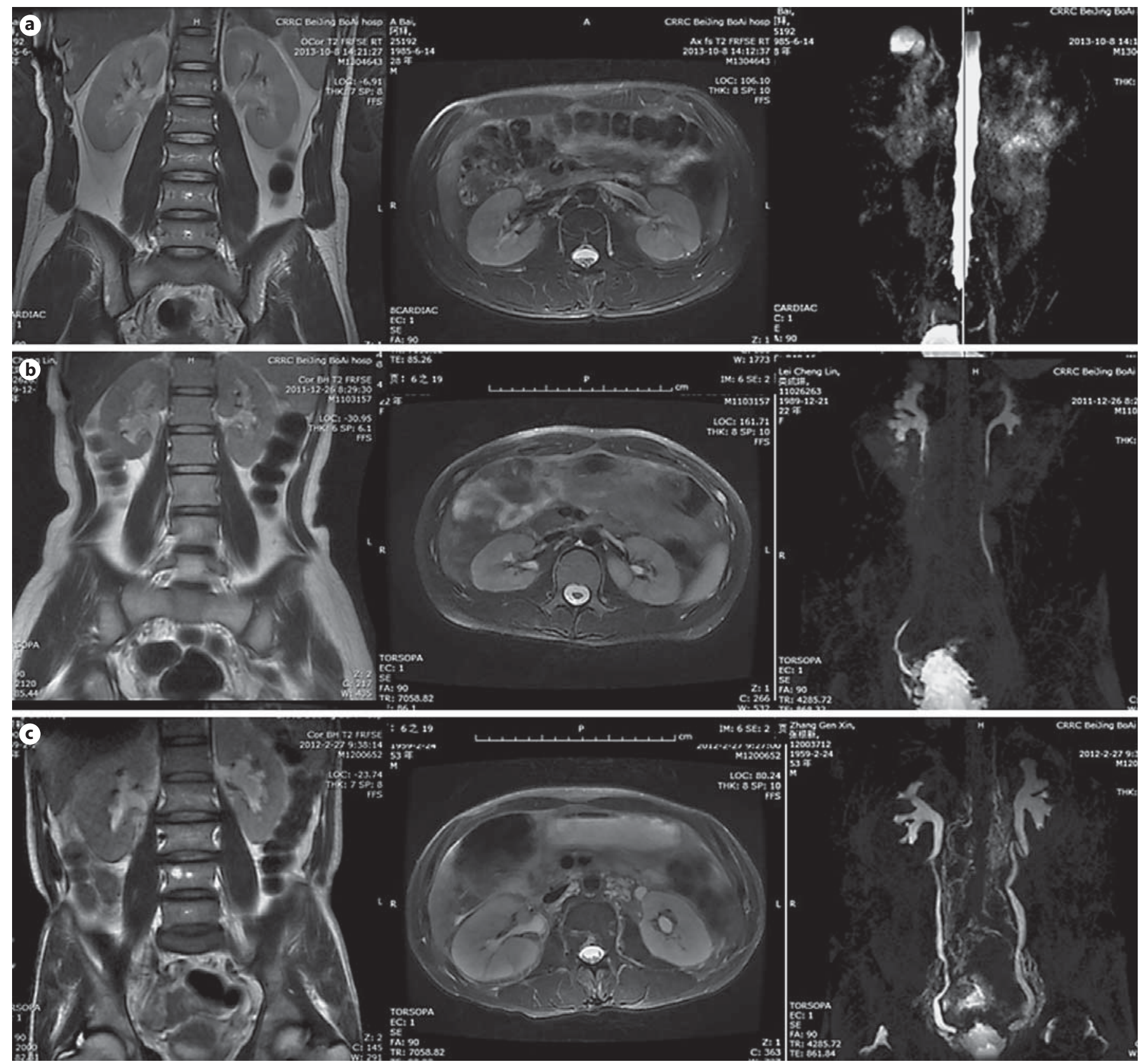

Fig. 1. MRU UUTD grades 0-2. a Grade 0 UUTD: MRU reveals no separation of the central renal complex of the kidneys and no dilation of the ureters. b Grade 1 UUTD: MRU reveals slight separation of the central renal complex of the kidneys and the ureters are $<7 \mathrm{~mm}$ in diameter. $\mathrm{c}$ Grade 2 UUTD: MRU shows that the renal pelvis of the left kidney is further dilated, a few calices may be visualized and the left ureter is $<10 \mathrm{~mm}$ in diameter. 

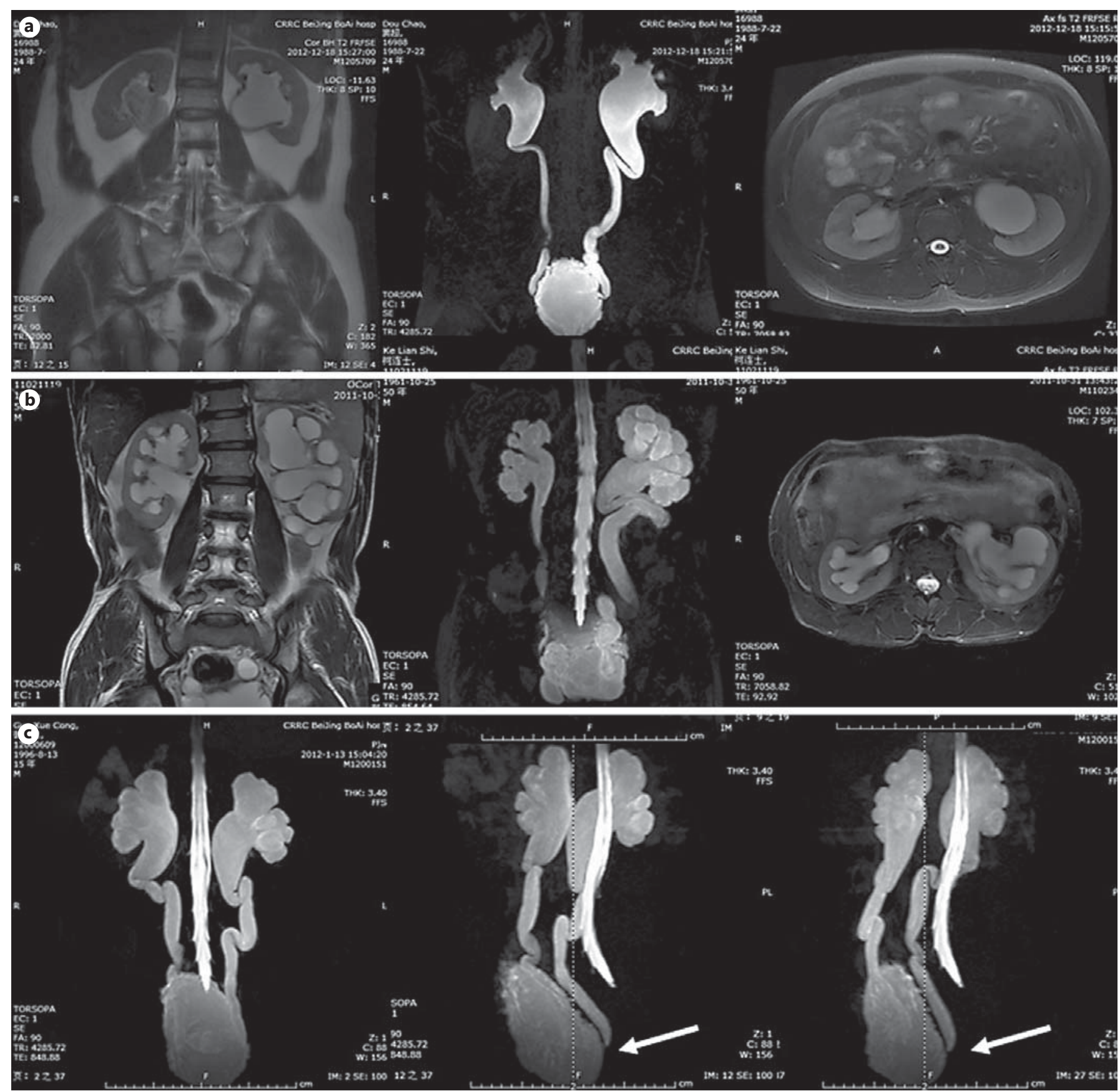

Fig. 2. MRU UUTD grades 3-4 and distal ureteral obstruction. a Grade 3 UUTD: MRU shows that the renal pelvis is dilated, there are fluid-filled calices throughout the left kidney, the renal parenchyma overlying the calices has thinned (renal parenchyma loss $<50 \%$ ), and the left ureter is tortuous and $<15 \mathrm{~mm}$ in diameter. b Grade 4 UUTD: MRU shows that the bilateral renal pelvises are seriously dilated, there are fluid-filled calices throughout the kidneys, the renal parenchyma over the calices is thinned (renal parenchyma loss $>50 \%$ ), and the bilateral ureters are severely tortuous and $>15 \mathrm{~mm}$ in diameter. c Distal ureteral obstruction: HN and UD can be displayed during $360^{\circ}$ rotation, and vesicoureteral junction stricture or obstruction can be clearly shown (arrows: left and right ureters).

Classification System for Urinary Tract Dysfunction in Neurogenic Bladder
Urol Int 2015;94:244-248 DOI: $10.1159 / 000365056$ 

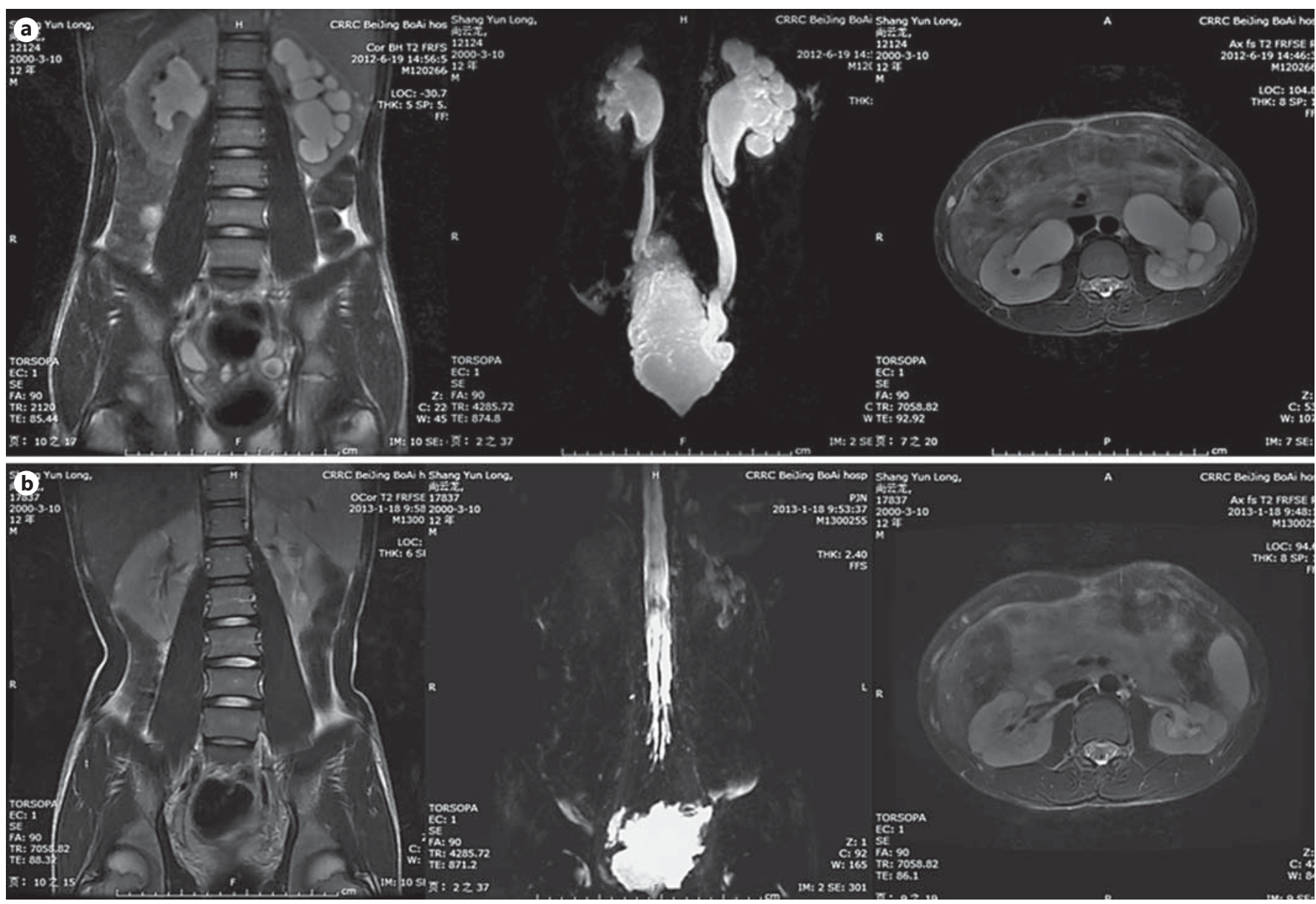

Fig. 3. Improvement of UUTD grades by MRU after 6 months of augmentation enterocystoplasty. a Preoperative UUTD grades of right and left kidneys were 3 and 4, respectively. b Postoperative UUTD grades of right and left kidneys became 0 and 1, respectively. A significant improvement is shown.

References
1 Stöhrer M, Blok B, Castro-Diaz D, et al: EAU guidelines on neurogenic lower urinary tract dysfunction. Eur Urol 2009;56:81-88.

2 Pannek J, Stöhrer M, Blok B, et al: EAU guidelines on neurogenic lower urinary tract dysfunction. 2011. www.uroweb.org/gls/pdf/ 17_Neurogenic\%20LUTS.pdf.

$\checkmark 3$ Duckett JW, Bellinger MF: A plea for standardized grading of vesicoureteral reflux. Eur Urol 1982;8:74-77.

4 Fernbach SK, Maizels M, Conway JJ: Ultrasound grading of hydronephrosis: introduction to the system used by the Society for Fetal Urology. Pediatr Radiol 1993;23:478-480.
5 Abrams P, Cardozo L, Fall M, et al: The standardisation of terminology of lower urinary tract function. Neurourol Urodyn 2002;21: 167-178.

6 Liao LM, Zhang F: Upper urinary tract dilation in the neurogenic bladder; in Santucci RA, Chen M (eds): Ureters: Anatomy, Physiology and Disorders. New York, Nova Science, 2012, pp 99-110. 